\title{
REPRESENTAÇÕES SOCIAIS DE RELAÇÕES DE TRABALHO: UM ESTUDO COM TRABALHADORES PRIMARIZADOS
}

SOCIAL REPRESENTATIONS OF WORK RELATIONS:

A STUDY WITH REINSOURCING WORKERS

\author{
Recebido em 16.09.2013. Aprovado em 12.04.2015 \\ Avaliado pelo sistema double blind review \\ DOI: http://dx.doi.org/10.12712/rpca.v10i1. 314
}

\section{Luiz Alex Silva Saraiva}

saraiva@face.ufmg.br

Universidade Federal de Minas Gerais, Belo Horizonte (UFMG), Belo Horizonte/MG, BRASIL

\section{Cássia Batista de Andrade Soares}

compras@fermag.ind.br

Faculdade de Ciências Administrativas e Contábeis da Fundação Comunitária de Ensino Superior de Itabira, Itabira/MG, BRASIL

\section{Elisângela Domingues Michelatto Natt}

elisdomingues@gmail.com

Universidade Federal de Minas Gerais, Belo Horizonte (UFMG), Belo Horizonte/MG, BRASIL

\section{Resumo}

Em face de efeitos negativos da terceirização, o processo inverso, a primarização, tem sido adotado por um número crescente de organizações. Nesse artigo, o objetivo é identificar as representações sociais das relações de trabalho de trabalhadores que se encontram em contexto de pós-primarização. A partir de entrevistas realizadas com profissionais que foram terceirizados e hoje são primarizados, evidenciou-se que, após a primarização, os entrevistados passaram a se sentir mais valorizados e reconhecidos, com elevação da autoestima e engajamento no trabalho. Conclui-se que o processo de primarização pode proporcionar melhorias impactantes tanto para as relações de trabalho quanto para a organização como um todo.

Palavras-chave: Representações sociais. Relações de trabalho. Primarização.

\begin{abstract}
Considering negative effects of outsourcing, the inverse process, reinsourcing, has been adopted by a growing number of organizations. In this paper, we deal woth identification of social representations of work relations from workers who are in a post-reinsourcing context. Starting from interviews with professionals who were outsourced and actually are reincsourded, data show that after reinsourcing, interviewers felt more valued and recognized, with elevation of self steem and engagement at work. We concluded that reinsourcing process can bring impacting improvements in work relations, as well to whole organization.
\end{abstract}

Keywords: Social representations. Work relations. Reinsourcing. 


\section{Introdução}

Com a reestruturação da economia brasileira nos anos 1990, houve aumento da competitividade, o que impactou as organizações nacionais. Buscando se adequar às novas condições de mercado, a terceirização foi um dos principais caminhos para reduzir custos e melhorar a eficiência produtiva das empresas. Contudo, essa alternativa em muitos casos resultou em precarização do trabalho, alta rotatividade, desemprego e, consequentemente, no aumento da exclusão social (BICUDO, 2003). Muitas das empresas que terceirizaram, por ter comprometido a qualidade na prestação de serviços, investiram no caminho contrário, na primarização, tendo em alguns casos trazido ao quadro funcional seus antigos terceirizados. Mesmo sendo comum associar a primarização a custos mais elevados, principalmente em relação ao pessoal, muitas empresas consideram o processo como uma oportunidade de crescimento. Essa crença está pautada na possibilidade de se obter maior harmonia entre as atividades produtivas e os ganhos relacionados à governança corporativa.

Para os trabalhadores, as mudanças proporcionadas pela primarização impactam diretamente as condições de trabalho, o que via de regra gera expectativas de melhorias quanto à precarização do trabalho provocada pela terceirização. Nesse sentido, parte-se do pressuposto de que o contexto de pós-primarização permite que as relações de trabalho adquiram novos significados para os trabalhadores antes terceirizados. A fim de compreender a dinâmica desses significados, entende-se que a teoria das representações sociais é uma adequada para a compreensão das implicações do senso comum, pois permitiria identificar o significado atribuído às relações de trabalho nesse contexto por um grupo específico.

Nesse artigo, o objetivo é identificar as representações sociais das relações de trabalho de empregados que se encontram em contexto de pós-primarização, um propósito relevante já que possibilita o entendimento dos aspectos subjetivos que perpassam a estrutura da organização. Para isso foi feito um estudo qualitativo, levado a cabo por meio de entrevistas semiestruturadas com trabalhadores terceirizados, material posteriormente trabalhado a partir da análise francesa de discurso com base em Pêcheux (2014).

Para discutir essa dinâmica observada e apresentar o percurso da pesquisa, o artigo está dividido em cinco seções, a começar por esta breve introdução, seguida do referencial teórico que embasou a pesquisa, no qual constam informações sobre relações de trabalho, teoria das representações sociais e primarização. Em seguida apresentamos o caminho percorrido em termos metodológicos. Posteriormente, são apresentadas as análises que resultaram de toda a investigação, em que se pontuam o que é ser primarizado, a organização do processo de trabalho, a gestão da força de trabalho, as de trabalho e de saúde do trabalhador e a regulação de conflitos, o que precede as considerações finais.

\section{As relações de trabalho}

As relações de trabalho passaram por uma série de transformações, já que para alcançar competitividade, as organizações tiveram suas estruturas flexibilizadas, o que ocasionou o comprometimento das condições de trabalho. Em meio a essas transformações, o significado do trabalho foi se redefinindo a partir das representações sociais dos trabalhadores inseridos em determinados contextos. Para Albornoz (1986), essa significação é importante porque a sociedade sem trabalho aparece como uma ameaça inquietante. Conforme Antunes (2002) é imprescindível entender as transformações ocorridas no mundo contemporâneo, bem como as implicações no mundo do trabalho. Segundo Galvão e Trindade (1999), as relações do trabalho vêm passando por significativas mudanças na estrutura estabelecida no período pósguerra, principalmente nos países capitalistas mais avançados (ANTUNES, 2002).

É nesse mesmo período que se consolida o sistema de relação de trabalho (GALVÃO; TRINDADE, 1999). Foi um processo marcado pela expansão da economia internacional, pela difusão do padrão de industrialização norte-americano, aumento da oferta de emprego e no poder aquisitivo das famílias e a ampliação dos serviços públicos. Nesse quadro, aumentou significativamente o número de trabalhadores, ressocializados por meio do trabalho na indústria e por processos de socialização externos às empresas, o que possibilitou a emergência de um novo proletário em larga escala, o que, conforme Carvalho Neto (2001), levou o sistema fordista a apresentar os primeiros sinais de crise de social e monetária. Isso acarretou um processo de desestruturação no mercado de trabalho, requerendo uma reestruturação produtiva e uma reconfiguração da relação entre o Estado, as organizações privadas, e os trabalhadores (GALVÃO; TRINDADE, 1999). 
No Brasil, contudo, somente durante o governo Collor se inicia esse movimento neoliberal. De acordo com Dalfior (2002), a abertura dos mercados, a desestatização e contenção dos gastos públicos, o desemprego e a exclusão social agravaram-se no país, consequentemente, as organizações precisaram ajustar sua estrutura a fim de reduzir os custos e continuar existindo. Com o respaldo do Estado, foram introduzidos os contratos temporários, possibilitando formas mais flexíveis de negociação nas relações de trabalho. Segundo Galvão e Trindade (1999), o estabelecimento desses contratos afeta negativamente os trabalhadores e as contratações coletivas são cada vez menos reguladas pelo Estado.

As relações de trabalho vivenciadas e produzidas pelos atores sociais, em seu processo de socialização coletiva no ambiente de trabalho, passam a ser desvalorizadas, deixando-se de levar em conta que são relações imbricadas por questões econômicas e políticas. Para Fischer (1987) é importante considerar que os papeis exercidos nas relações de trabalho são opostos e complementares e constituem-se a partir de variáveis como a organização do trabalho, a gestão da força de trabalho, os processos de regulação de conflitos e as condições e saúde do trabalhador, sofrendo impactos nos contextos macro, como o da política, da economia, da tecnologia e da cultura (MELO; CARVALHO NETO, 1998). Para Melo (1991), é na dinâmica das relações de trabalho que se ajustam os interesses das partes envolvidas, sendo necessária a existência de um conjunto de normas que regulem as condições gerais.

Melo (1991) argumenta que a definição das relações de trabalho como relações trabalhistas, enquadra o assalariado em um estatuto ou código de trabalho determinado, que desconsidera o emprego envolvendo as questões subjetivas. Assim, são estabelecidos, muitas vezes, sistemas coercitivos e instrumentais, em que as formas de controle assumem maneiras sutis de coerção, incorporando sistemas participativos, persuasivos e manipuladores. Entretanto, a autora aponta que as condições de trabalho e saúde podem refletir desgaste quando a subjetividade do trabalhador não é levada em conta. Questões como o conflito e as relações de poder podem significar a existência de interesses divergentes, demandando um sistema de regulação que assegure o funcionamento desse sistema complexo, mantendo em equilíbrio as relações composta por interesses antagônicos que coexistem nos processos de cooperação. Tais sistemas de regulação podem funcionar em meios institucionalizados, em que a relação de um conjunto de formas estabelecidas pela legislação e/ou pelo costume, ou em meios não institucionalizados em que os procedimentos e ações se referem a práticas que possibilitam a expressão e o espaço para ambas as partes da relação (MELO, 1991).

Os processos de regulação são provisórios e dependem das relações e características próprias aos grupos particulares. Tais relações se modificam constantemente, bem como as racionalidades e as relações de poder (MELO, 1995). Nesse sentido, deve se considerar que o sistema de regulação comporta uma diversidade de preferências, de valores e interesses em que se encontram pontos comuns. Assim existem regras, de formas de regulação conjuntas, pontuais e, às vezes, ambivalentes. Os comportamentos são racionalizados no espaço da regulação e nunca são iguais, expressando lugares de poder nas relações de trabalho e práticas de controle por parte das organizações. Aspectos como os traços da personalidade, a própria história e as posições individuais, são acompanhados pela diferenciação das situações de trabalho e pelas condições vivenciadas no interior de uma mesma empresa. Esse emaranhado de influências pode até ser aparentemente cerceado pelos processos de regulação colocados em prática pela empresa; no entanto, é pela lógica do indivíduo, expressa no seu espaço de subjetividade que se realizam as práticas efetivas no ambiente de trabalho. Nesse sentido, é no interior e em meio às particularidades de cada organização que se constroi o sistema real de regulação (MELO, 1995), o que destaca a força das representações sociais.

\section{Teoria das representações sociais}

É na vida em sociedade que estão fundadas as representações sociais. De acordo com Sá (1993), em todos os lugares e ocasiões onde há reunião e comunicação entre as pessoas, há alguma forma de representação social, já que são elas que constroem e detém o poder sobre a realidade e a vida cotidiana. Para Moscovici (2007), qualquer indivíduo é dotado, individual e coletivamente, por palavras, ideias e imagens que penetram seus olhos, ouvidos e mente, mesmo quando não há intenção. Isso ocorre porque as representações possuem funções convencionais - convencionam os objetos, dando-lhes uma forma definitiva e localizando-os em uma categoria, partilhada com um grupo de pessoas - e prescritivas, já que se 
impõem aos indivíduos com uma força irresistível e uma combinação de estrutura presente anterior ao pensamento e uma tradição que determina o que pensar. Assim, estruturalmente, as representações não necessariamente se relacionam a maneira de pensar, pois são transmitidas como o produto de uma sequência de elaborações e mudanças ocorridas no decorrer do tempo, constituindo-se como produto de sucessivas gerações (MOSCOVICI, 2007).

Segundo Sá (1993), é no âmbito da sociologia e da antropologia que surge o conceito de representação social. Mas só a partir dos trabalhos de Moscovici que se pontua formalmente o conceito. Em seus trabalhos o estudioso tomou como referência as representações coletivas trabalhadas por Durkheim, contudo, diferente dele, Moscovici (2007) explorou a variação e a diversidade das ideias coletivas na sociedade. Enquanto para Durkheim a representação coletiva tinha um caráter conservador e apresentava-se como formas de compreensão coletiva e estáveis (GOMES; MENDONÇA; PONTES, 2002), para Moscovici (2007) as representações são constituídas na própria construção da sociedade, no solo político, científico e humano, e nem sempre tem tempo suficiente para serem sedimentadas completamente tornandose tradições imutáveis. A particularidade com que se instauram as representações é proporcional à heterogeneidade e à flutuação dos sistemas unificadores, como as ciências oficiais, as religiões, as ideologias oficiais e são necessárias mudanças para que elas possam penetrar na vida cotidiana, tornandose parte da realidade comum.

Segundo Xavier (2002), o principal objetivo de Durkheim era encontrar o que fornecia unidade à vida social, enquanto Moscovici (2007) entendia o social como divergente do coletivo de Durkheim, pois para ele, o conceito de representações coletivas de Durkheim promovia a separação radical entre representações coletivas e individuais, enquanto sua perspectiva é bilateral, partindo do princípio de que a constituição das representações sociais é construída pelo conhecimento elaborado e partilhado socialmente, e também pela realidade psicológica e analógica do indivíduo. As representações não são criadas do nada; adquirem vida própria, circulando e se encontrando, se atraindo ou repelindo, possibilitando o surgimento de novas representações, enquanto as antigas desaparecem. Consequentemente, para que seja possível compreender uma representação, é preciso buscar conhecer como ela nasceu e como outras representações deram lugar a ela. Ademais, elas podem ser reforçadas pela tradição a partir de seu compartilhamento por todos, constituindo assim, o que Moscovici (2007) chamou de realidade sui generis.

Moscovici (2007) focou em uma psicologia social do conhecimento, produzido por meio da interação e comunicação do saber prático, e cuja expressão está ligada aos interesses do indivíduo. No intuito de fundamentar sua teoria, compreendeu que o primeiro processo para que uma representação social surja é a ancoragem, o momento em que algo estranho e perturbador é elevado a uma categoria conhecida, por um mecanismo que permite ancorar as ideias estranhas, transformado-as em categorias e imagens comuns, em um movimento de familiarização do nãofamiliar. O segundo processo é o da objetivação, que transforma algo abstrato em algo quase concreto, a partir da transferência do que está na mente para algo que existe no mundo real, permitindo ao imaginário assumir a realidade de algo concreto, unindo a ideia de não-familiaridade com a de realidade e reproduzindo uma imagem (MOSCOVICI, 2007).

Cavedon e Pires (2004) sustentam que ancorar é classificar, nomear alguma coisa, é que o indivíduo faz ao dar nome a algo, imaginando-o e representando-o, estabelecendo um valor positivo e negativo, enquanto que a objetivação é a descoberta da qualidade icônica de uma ideia, transformando algo abstrato em material. Nesse sentido, as imagens, ideias e a linguagem compartilhada de um grupo podem direcionar os comportamentos e as condutas que o perpassam (MOSCOVICI, 2007). Assim, cada grupo constroi um significado a partir de conhecimentos compartilhados sobre um fato ou ocorrência que se adapta ao contexto (ESPÍNDULA; SANTOS, 2004). Para Teixeira et al. (2002), isso faz com que as representações sociais constituam formas de conhecimento socialmente elaboradas que, ao serem produzidas pelos grupos de indivíduos, comunicam aquilo que antes lhes era estranho, não familiar. Porém, para que se compreenda o processo, é preciso que se descubra quais as características não familiares motivaram a ancoragem e a objetivação da representação constituída, com a observação do processo durante sua emergência na esfera social (MOSCOVICI, 2007).

Conforme Moscovici (2007), as representações sociais podem influenciar o comportamento do indivíduo que faz parte de um coletivo. Esse fenômeno se explica porque as representações são criadas internamente, mentalmente, mas a partir do processo coletivo, 
que penetra de forma determinante no pensamento individual. Assim, a representação aparece quase como objeto material, devendo ser entendida, portanto, como teorias sobre os saberes populares e do senso comum, uma vez que são elaboradas e partilhadas pelo grupo, com a finalidade de construir e interpretar o real, levando os membros desse grupo a produzirem comportamentos e interações com o meio (OLIVEIRA; WERBA, 2000). Assim, as representações sociais de um grupo constituem, a partir do significado atribuído a um objeto, opiniões, sentimentos e ideias, o que permite que sejam entendidas como meios de interpretar sentimentos, condutas e palavras (MINAYO, 2006). Para Xavier (2002), as representações sociais são um sistema de interpretação da realidade, organizando as relações do indivíduo com o mundo e orientando suas condutas e comportamentos no meio em que se insere.

As representações sociais podem, a qualquer momento, tomar forma e configuração específicas (XAVIER, 2002). Trata-se de um conhecimento estruturado, determinante no modo como os indivíduos veem e reagem diante da realidade (CAMPOS; ROUQUET'TE, 2003), e tem como objetivo abstrair sentido do mundo e nele introduzir ordem e percepções, reproduzindo esse mesmo de uma forma significativa (MOSCOVICI, 2007). Assim, as representações igualam toda imagem a uma ideia e toda ideia a uma imagem, apresentando-se como mecanismos mentais que constroem uma figura, dando-lhe significados e interpretações. Nesse sentido, as representações das relações de trabalho de um grupo de trabalhadores podem refletir a realidade por eles vivida, já que permite conhecer o modo como um grupo de indivíduos constroi um conjunto de saberes, expressando a identidade do grupo e definindo, em cada momento histórico, as regras para o convívio social (OLIVEIRA; WERBA, 1998). São as representações sociais as responsáveis por dar coerência ao universo vivido, criando referência para atitudes dos indivíduos (ESPÍNDULA; SANTOS, 2004) e permitindo o conhecimento das práticas em um determinado contexto, a partir da descrição da realidade ou de um fenômeno (OLIVEIRA; WERBA, 1998).

Entretanto, Cavedon e Ferraz (2005) alertam que as representações são imagens mentais elaboradas pelo senso comum, podendo ser determinadoras de ações, obstruindo ou viabilizando implementações estratégicas no intuito de atingir os objetivos e metas organizacionais, uma vez que no cotidiano das organizações, os sujeitos produzem o saber prático, criando seus próprios significados do contexto. Vale ainda ressaltar que as representações sociais devem ser compreendidas a partir do seu contexto de produção, já que são fenômenos sociais e que, mesmo acessadas a partir do seu conteúdo cognitivo, são construções do sujeito como ser social, sendo sempre construções contextualizadas e resultantes das condições de seu surgimento e circulação (SPINK, 1993). É importante, assim, que se busque conhecer a história social e as condições que envolvem o grupo investigado, e que nesse caso, trata-se do contexto primarização, conceito do qual trataremos a seguir.

\section{Primarização}

O sistema taylorista/fordista baseou-se na produção em massa, estruturada a partir da padronização e verticalização do processo produtivo. Esse tipo de estrutura foi representado pela produção da indústria automobilística, em que todo o processo produtivo era realizado na própria empresa (ANTUNES, 2002). Com a crise econômica e a reestruturação produtiva, ocorridas a partir do final dos anos 1960, as empresas precisaram buscar novas formas para manter a competividade, o que contribui para a quebra do modelo verticalizado. A saída foi buscar a horizontalização dos processos, isto é, passaram a adotar a transferir algumas de suas atividades a terceiros. Conforme Castro e Bim (2007), diversas organizações aderiram à terceirização sem, contudo, realizar a análise dos seus desdobramentos, o que ocasionou situações negativas, decorrentes de contratações sem avaliação criteriosa, em que parte da produção foi confiada a prestadores de serviços não qualificados, com considerável queda na qualidade dos produtos desenvolvidos por terceiros.

Com a queda na qualidade, surgiu a preocupação com a qualificação dos profissionais executando as mais variadas tarefas nas organizações. Se inicialmente os custos de produção mais baixos eram um atrativo para que se terceirizassem os processos, posteriormente houve um aumento incisivo desses custos, como consequência das reclamações e necessidade de substituição de produtos. Os dirigentes das organizações novamente viram-se preocupados em relação à competitividade e, a fim de tornarem-se competitivos, adotaram a primarização. Essa alternativa técnica de gestão ressurge em contraposição a terceirização, que fez emergir empresas que, em busca de menores custos, não investiram na qualificação da 
mão-de-obra, o que de acordo com Saraiva e Mercês (2013), ocasionou a queda na qualidade dos serviços prestados, comprometendo a sobrevivência da empresa contratante. Assim retoma-se a primarização, também chamada de desterceirização (outsourcing reverse ou reinsourcing), e definida por Castro e Bim (2007), como o processo inverso à terceirização das atividades de uma organização e que traz de volta, para o seu quadro funcional, as atividades que anteriormente eram executadas por terceiros.

Com a adoção da primarização a estrutura horizontalizada é verticalizada, resultando em um processo no qual as organizações tornam a gerir, por conta própria, as atividades antes delegadas para terceiros, passando a ter novamente, o total controle sobre elas (MAGALHÃES et al., 2011). Esse tipo de estrutura organizacional vem sendo retomada com frequência pelas organizações e, no Brasil, todas as capitais - de acordo com a Pesquisa de Emprego e Desemprego (PED) e com o Departamento Intersindical de Estatísticas e Estudos Socioeconômicos (DIEESE) - apresentaram, no período de 1996 a 2005, o fenômeno da primarização. Estima-se que, nas empresas privadas, o processo tenha se iniciado a partir de 2005, e que impactou todos os níveis das organizações, do chão de fábrica à comercialização do produto final. Por se tratar de um fenômeno recente, ainda são poucos os trabalhos nesse sentido, com exceção de Magalhães et al. (2011), uma lacuna que estudos como este pretende diminuir. A metodologia será apresentada a seguir.

\section{Percurso metodológico}

No intuito de alcançar as dimensões subjetivas nos processos de primarização, decidiu-se adotar para a pesquisa a perspectiva qualitativa, mais adequada ao estudo das representações sociais, contribuindo para que se possa identificar, com profundidade, o universo de significados, práticas e atitudes dos trabalhadores envolvidos no processo de primarização. Para Minayo (2007), trata-se de um tipo de pesquisa que corresponde a um espaço mais profundo das relações, dos processos e dos fenômenos, que não podem ser quantificados.

A organização pesquisada, uma faculdade - alfa - foi criada em 1993, e por se tratar de uma instituição comunitária, composta pela Prefeitura Municipal, Câmara Municipal, Diocese da região e uma grande empresa atuante na região, desenvolve serviços educativos sem fins lucrativos, sendo todos os excedentes financeiros reaplicados na própria organização. Atualmente, oferece 17 cursos de graduação, além dos cursos de pós-graduação e projetos sociais e comunitários. Conta com mais de 250 profissionais entre corpo docente, técnicoadministrativo, limpeza e vigilância. Em 2004, a organização rescindiu o contrato com a empresa que prestava serviços terceirizados de limpeza e de segurança e se reuniu com os terceirizados para expor as propostas de trabalho. Em 2005, a contratante primarizou todos os 39 empregados terceirizados e após esse período metade dos trabalhadores que passaram pelo processo, permaneceu no quadro funcional da empresa.

Os sujeitos da pesquisa foram selecionados entre empregados da limpeza e vigilância, que passaram pelo processo de primarização e trabalharam na empresa terceirizada por mais de dois anos. Embora na organização 43 pessoas atuem na área de limpeza e vigilância, o universo da pesquisa foi composto por 19 empregados, pois apenas esses trabalhavam anteriormente para a empresa terceirizada, passando a integrar o quadro de empregados primarizados da empresa contratante. Destes, sete apresentaram conhecimento suficiente em relação o processo de primarização, e por isso foram especificamente abordados.

Para a coleta de dados foram realizadas entrevistas individuais semiestruturadas, o que permitiu maior flexibilidade e oportunidade para a coleta e avaliação dos dados relevantes não documentados. O instrumento construído para nortear as entrevistas tinha os seguintes blocos temáticos: a) trajetória; b) regulação de conflitos; c) condições de trabalho e saúde do trabalhador; d) organização do processo de trabalho; e) gestão da força de trabalho; e f) trabalho e primarização. A análise dos dados foi realizada a partir da perspectiva francesa de análise do discurso particularmente baseada nas ideias de Pêcheux (2014). De acordo com Fiorin (2000), essa abordagem procura compreender os sentidos atribuídos pelos indivíduos aos temas apresentados, por meio das falas e, sobretudo, das expressões, possibilitando a interação entre o pesquisador e o entrevistado, e permitindo a interpretação do discurso considerando a subjetividade. As técnicas usadas foram a análise lexical e a interdiscursividade. A seguir serão apresentadas as representações e sua análise. 


\section{Representações sociais do trabalho em um contexto de primarização}

Os depoimentos usados foram selecionados por se relacionarem com as representações sociais do trabalho em um contexto de primarização. Trabalhou-se, no final, com cinco categorias de discurso, a saber: a) Ser primarizado - status, reconhecimento e estabilidade; e b) Organização do processo de trabalho; c) Gestão da força de trabalho; d) Condições de trabalho e de saúde do trabalhador; e e) Regulação de conflitos, a seguir discutidas.

\section{Ser primarizado - status, reconbecimento e estabilidade}

(01) [Com a primarização] mudou muito, porque o seguinte... eu fiquei mais... en procuro fazer o serviço acho que até melhor, do que quando era da terceirizada eu, hoje eu tô dentro, eu tô aqui... (Entrevistado 1)

(02) Eu me senti, mais responsável, mais responsável pelo trabalho, eu nunca fiz isso, mas antes que não era alfa... (Entrevistado 4)

De acordo com os depoimentos (01) e (02), após o processo de primarização, os enunciadores explicitamente se sentiram mais motivados em executar seu serviço com maior qualidade e responsabilidade, devido à percepção de se sentirem, efetivamente, parte da empresa. Há interdiscursividade entre a situação atual e a anterior nos dois depoimentos, o que sugere que, quando terceirizados, os entrevistados não agiam da forma atual.

(03) Agora, as pessoas, eu sinto assim, que olha de fora me vê assim eles me enaltecem mais por eu ser funcionário da alfa, você entendeu, as pessoas que de fora eu estando com uniforme da alfa me olham diferente se eu estivesse com uniforme da delta ${ }^{1}$, automaticamente a gente se sente assim. (Entrevistado 1)

(04) O uniforme da alfa parece que trouxe uma melhora para nós, os alunos trata a gente muito bem, ta sabendo que estamos trabalhando na alfa. Então, logo nós não estamos na empreiteira, estamos na alfa onde estão estudando todo mundo e a gente, antes chamavam agente de colarinho vermelho, aquele trem todo. O uniforme da delta a gola é vermelha, ai mudou, agora estamos com o uniforme da alfa, melhorou bastante. (Entrevistado 2)
Os fragmentos discursivos (03) e (04) explicitam reconhecimento por parte dos demais, de sua condição superior como primarizados. Isso se manifesta não apenas pelo vínculo contratual, quanto por um artefato, o uniforme da empresa, que aumentou a autoestima dos empregados à medida que eram invisíveis (COSTA, 2004) quando usavam o da terceirizada. Em outras palavras, ao carregar o nome alfa, agora podem ser enxergados. O uniforme atua como fator de status social, conferindo satisfação aos entrevistados. Outro aspecto do texto (04), é que, enquanto terceiros, os trabalhadores eram reconhecidos apenas pelo nome da terceirizada, ou por colarinhos vermelhos, isto é, desapareciam simbolicamente. Isso é confirmado pelo depoimento (05):

(05) Hoje todo mundo me chama pelo nome [...] assim eu tenho vários apelidos, mas sempre assim, agora na delta não, eram pouquíssimos, hoje não, pode generalizar praticamente todo mundo me chama pelo nome, [...] a auto-estima da gente fica muito mais elevada. (Entrevistado 1)

(06) A gente teve assim, credibilidade no meio das pessoas, criou um vínculo maior com as pessoas, elas passaram a acreditar mais no nosso serviço, como pessoa, como colega de serviço, como profissional, como família, porque a alfa é uma verdadeira família. (Entrevistado 7)

O texto anterior explicita como a questão da identificação, de ser chamado pelo nome tem um significado relevante para esses empregados. Percebem que, após a primarização, são reconhecidos individualmente, todos os reconhecem como indivíduos, não como simples componentes de um grupo que anteriormente era o dos terceirizados. No fragmento discursivo (06), a identificação traz outro efeito: a percepção de o reconhecimento quanto ao trabalho em si, uma vez que após a primarização, conquistaram confiançaecredibilidadedos empregados da empresa e do público externo. Primarizados, tais empregados se inteiram dos assuntos gerais da empresa, respondem por uma parte dela, e isso faz com que as pessoas acreditem mais no seu trabalho, havendo, por isso, maior respeito e aproximação. O afastamento anterior ocorria, inclusive, por uma questão legal, já que apenas o preposto da contratada

\footnotetext{
${ }^{1}$ Delta é o nome fictício da empresa terceirizada que prestava serviços de limpeza e segurança para alfa, e que empregava todos os entrevistados como terceirizados.
} 
poderia entrar em contato com os terceiros, sob pena de ser caracterizado vínculo empregatício.

Um dos mais positivos e evidentes aspectos ligados à primarização é, para os entrevistados, a aquisição de maior segurança no emprego, o que os inquietava na terceirizada. No processo de primarização, tal fato é visto como uma vantagem, trazendo conforto e estabilidade:

(07) A alfa é uma comunidade já oferece mais tempo para trabalhar. Na terceirizada não era garantido, na alfa eu me sinto seguro. (Entrevistado 3)

(08) Trouxe uma certa segurança pra gente, sabe?... Na terceirizada a gente fica com o coração na mão não sabe se vai estar aqui amanhã, mas o cara tem que confiar nele, que ele é um profissional. (Entrevistado 7)

Os fragmentos discursivos (07) e (08) explicitam uma interdiscursividade entre a instabilidade e insegurança do passado na empresa terceirizada e a estabilidade pela percepção de segurança na condição atual. Com a primarização, passaram a se preocupar apenas com a questão profissional, isto é, com a qualidade da prestação do serviço para garantia de sua permanência, o que desperta no empregado confiança e fidelidade à empresa, devido à esperança de vínculo por um período maior. A seguir, serão apresentadas análises de cada instância das relações de trabalho.

\section{A organização do processo de trabalho}

A organização do processo de trabalho estabelece os meios para as organizações alcançarem a otimização da sua produção (FLEURY, 1987). Com a primarização, a alfa usa desses meios para melhor organizar a sua produtividade, sendo os empregados um fator fundamental, pois a forma como esses a representam se reflete no seu desempenho.

(09) Porque nós agora temos uma área para trabalhar, porque quando era a terceirizado nós não tínhamos um lugar certo de trabalhar e hoje, nós temos. Hoje nós temos um prédio para cuidar, hoje nós temos aparelho para olhar. (Entrevistado 2)

(10) Agora está mais organizado, antes era muito desorganizado, agora não, agora tem organização, cada um tem seu posto, cada um tem que dar satisfação do seu posto [...] chega no final do turno entrega ele sem alteração, então cada um tem a sua responsabilidade. (Entrevistado 6)

Pelos depoimentos (09) e (10), percebe-se que, após a primarização, houve divisão das tarefas, com o estabelecimento de funções específicas para cada empregado, o que só é possível com a possibilidade de organização e de responsabilização pelas atividades. Possivelmente essa visão positiva sobre a organização com que agora contam eleva a qualidade da prestação de serviços pelo planejamento e controle das tarefas. As empresas terceirizadas, como não prestam serviço para uma única empresa, diversas vezes deslocam os empregados para suprir uma demanda de outro contrato. Assim, por não terem um local fixo para prestar serviço e por possuírem muitas funções, isso reforça a sensação de instabilidade:

(11) E...assim na delta tinha aquilo de.. en tava lá em casa tranqüilo faltou um aqui, já tava chegando e chamando pra vim trabalhar, vinha com maior prazer. Aqui não já me avisam com antecedência, eu tenho meu local fixo de serviço né, minhas funções são estabelecidas. Na delta se precisasse trazia outro pra cá, en já ia lá pra..._agora eu sei o que vou fazer né, dá segurança para gente... (Entrevistado 1)

Conforme o texto (11), trabalhar em um local fixo significa sentir-se seguro, pois cada empregado assume sua responsabilidade, impossibilitando, dessa forma, assumir erros por ele não cometidos. A outra face do processo é o incremento do controle sobre seu trabalho:

(12) Hoje é bem mais controlado, hoje a gente trabalha com a regra da vigilância mesmo, tem bierarquia, as funções agora são bem definidas. $O$ controle é bem mais rígido, tem o relatório que a gente coloca tudo o que acontece aqui dentro... (Entrevistado 5)

(13) A jornada é mesma que antes 12/36, porém eu acho que na alfa a gente trabalha muito mais, [é] mais cobrado, o estresse é maior, devido ao andamento da alfa... (Entrevistado 6)

Os relatos (12) e (13) são explícitos a respeito do aumento do volume de trabalho, pois agora se vinculam 
a uma organização mais complexa. Ao mesmo tempo, consideram-se, após a primarização, mais preparados e qualificados para atender à demanda, mesmo que isso signifique trabalhar sob maior pressão. A organização também gerou expectativas, como a de aumento de salário, o que não se tornou realidade:

(14) Eu esperava aumento de salário, eu esperei muita coisa, que até agora pra mim não veio melhoria, pra mim não, a questão de salário entendeu, eu acho que pela cobrança que a gente tem aqui a gente deviria ganhar um pouquinho mais, na alfa a gente está sendo muito mais cobrado... (Entrevistado 6)

Pelo depoimento (14), é possível identificar a frustração do enunciador quanto ao salário que passou a receber após a primarização. A insatisfação se deve a uma expectativa de que seriam mais bem remunerados - uma vez que se tornaria empregado de uma empresa com capacidade para tanto - associada a um aumento de cobrança no trabalho. Daí acreditar que deveria receber mais por isso.

(15) Na delta quando a gente fazia hora extra, recebia [...]100\% e agora na alfa, a hora que nós fazemos é compensada em folga, então né. (Entrevistado 2).

(16) Diferente faz horas extras, mas só recebe em folgas. Mas a delta era melhor que pagava horas extras. (Entrevistado 3).

Conforme os depoimentos (15) e (16), a percepção de queda no salário decorre do fato de a alfa não pagar horas-extras, e adotar regime de compensação de horas. Os entrevistados, mesmo tendo tido aumento com a primarização, julgam a remuneração pelo valor líquido do salário. $\mathrm{Na}$ delta, eles recebiam horas-extras devido ao elevado volume de trabalho, o que resultava em um valor significativo, o que os faz rejeitar a ideia de folgas como ganho, por conta de estarem acostumados a trabalhar ininterruptamente. Mas como esses empregados são gerenciados?

\section{A gestão da força de trabalho}

A gestão da força de trabalho estimula os empregados, colocando-os para trabalhar (MELO, 1991). Com a primarização, tal aspecto é ressignificado pelos trabalhadores:

(17) O contato na terceirizada era muito bom, eu conheço bem o temperamento dele né, é o seguinte ele cobra, ele era duro. Aquilo ali o que é do serviço ele cobrava mesmo, não tem essa, nem aquela. Mas é o seguinte, ele quase caía no tapa com a gente, mas assim é aquilo, é o serviço, amizade, amizade serviço à parte. Então assim já cobrava da gente, ficava vermelho e se não mudasse realmente ele era bem enérgico. (Entrevistado 1)

Conforme o depoimento (17), o relacionamento entre chefia e subordinado era baseado em autoritarismo, com o uso de gritos e de rispidez. Para alcançar os resultados, a chefia se relacionava de maneira enérgica com os empregados. O entrevistado explicitamente julga que se tratava de um relacionamento "muito bom", mas, ao mesmo tempo, deixa implícita a questão de serem impedidos de manifestar (conforme seleção lexical "não tem essa e nem aquela"), uma contradição possivelmente relacionada a um contexto de baixa qualificação de mão de obra, na qual esse tipo de relacionamento "duro" é tolerado.

(18) Melhorou porque trocamos de chefia, o pessoal aqui é mais legal que o da delta, não tem aquela cobrança, aquele trem encheção de saco, então a gente trabalha mais tranqüilo, cabeça mais fresca, não tem problema. (Entrevistado 2)

(19) Fiquei mais tranqüilo, aqui é um lugar que não manda a gente embora à toa, o pessoal conversa bastante dá muita chance antes de mandar embora, ajuda os funcionários, chega orienta. (Entrevistado 6)

Com a primarização, os entrevistados perceberam melhorias no relacionamento com os superiores hierárquicos, uma vez que, quando eram terceirizados, se incomodavam com o nível de cobranças. Eles hoje são mais tranquilos, pois existe diálogo. Em parte isso é necessário porque eles recebem mais treinamento do que no passado:

(20) Eu acho que passando de uma empresa pra outra foi tudo igual né, eu acho que a vantagem que eu tive foi os cursos que eu fir que foi o treinamento de cães e resgate, eu fui privilegiado nesses dois cursos. (Entrevistado 7) 
O depoimento (20) classifica explicitamente como vantajoso o fato de ter passado por treinamentos, um ganho para os primarizados. O treinamento pode constituir um estímulo, pois estar mais preparados faz os empregados se sentirem "privilegiados", como colocado.

(21) Eu visto a camisa, eu visto, me cobram eu dou satisfação, não importa o salário, eu to vestindo a camisa do mesmo jeito. Tanto é que eu ganhei como funcionário homenageado, tanto é que ninguém da segurança ninguém ganhou, então é porque o pessoal gostou do men trabalho. (Entrevistado 6)

(22) Você tem que receber críticas e elogios né, ai o retorno, tipo, no MEC a gente recebeu elogios porque foi classificado como bom.... pra mim é um retorno do meu trabalho, nós somos um grupo né? (Entrevistado 4)

Os entrevistados se tornaram visíveis a partir da primarização e, com isso, além de serem avaliados, também passaram a ser homenageados, uma espécie de retorno por apresentarem esprit de corps. Os elogios recebidos no trabalho são significativos, e atuam reforçando seus vínculos pessoais e profissionais para com a organização.

\section{As condições de trabalho e de saúde do trabalhador}

A maneira pela qual as condições de trabalho e de saúde do trabalhador se apresentam nas organizações pode ser determinante para a satisfação dos empregados (MELO, 1991).

(23) Em termos de EPI a segurança nossa passou a ser melhor, antes para limpar uma janela tinha que apoiar em um lugar de segurança hoje em dia para limpar temos que usar cinto de segurança, luva, né? Antes era muito difícil ter, mas agora melhorou. (Entrevistado 2)

Em relação ao fornecimento de EPI, o entrevistado explicita uma melhoria, uma vez que antes não usava os equipamentos necessários para garantir a segurança no trabalho, isto é, dispunham de precárias condições de segurança. Trabalhar sem segurança significa correr risco de acidentes, o que levava a executarem algumas de suas tarefas com receio, possivelmente prejudicando os resultados. Com a primarização, relatam que os equipamentos são fornecidos, o que minimiza o risco e proporciona condições para executarem suas tarefas com segurança.

(24) Antes acostumava atrasar uns dois dias, mas saia. $\mathrm{Na}$ alfa não, é sempre em cima, nunca atrasou. (Entrevistado 2)

(25) Com relação ao pagamento, é o único lugar que eu trabalhei que nunca recebi atrasado foi aqui na alfa, décimo terceiro é tudo certinho. (Entrevistado 6)

Com relação à pontualidade do pagamento do salário, os depoimentos (24) e (25) atestam que, com a primarização, o salário passou a ser pago pontualmente, o que, para esses trabalhadores, é um ponto positivo em face dos atrasos ocorridos na empresa terceirizada. Possivelmente pelo fato de a empresa cumprir suas obrigações, eles se veem obrigados a cumprir as suas. Tais obrigações incluem aspectos relacionados a exames de saúde:

(26) Fazia, isso fazia tudo, quando você vai ser despedido, faz exame pra ver se você está apto a entra ou pra sair, é tudo a mesma coisa. (Entrevistado 4)

(27) Quanto à questão de saúde no serviço, para segurança, no caso de final de semana a gente não tem ninguém não tem um carro disponivel, claro que tem SAMU, mas... O uniforme a gente recebi tudo direitinho, coturno tudo. (Entrevistado 6)

O texto (26) explicita que, quanto à exigência de exame médico, tanto a terceirizada quanto a primarizada cumpriram os aspectos legais. Porém, o depoimento (27) denuncia que não existe suporte para segurança de saúde na empresa, principalmente no final de semana, o que faz com que ele se sinta desprotegido quanto à sua saúde.

(28) Não tenho conhecimento [da CIPA], na alfa, en imagino que tem, pelo tamanho ela tem. Na delta nunca comentou com a gente não, nunca foi falado sobre isso não, se tinha se não tinha. (Entrevistado 3)

O entrevistado desconhece a CIPA, mas acredita que ela exista. Embora na alfa a percepção seja de 
mais segurança no trabalho por contarem com EPI adequado, a empresa deixa a desejar na garantia da saúde do trabalhador no local de trabalho, o que pode provocar absenteísmo devido a acidentes eventuais e até mesmo ações judiciais em face do direito à saúde no trabalho não estar plenamente assegurado.

\section{A regulação de conflitos}

Conforme Melo (1995), os conflitos nas organizações ocorrem devido à existência de interesses divergentes, o que pressupõe o desenvolvimento de um sistema para sua regulação.

(29) Uma vez [...] teve um estagiário tava me dando ordem, aí minha chefe foi e falou com a responsável dele, que o estagiário tinha que me respeitar porque eu era funcionário tanto quanto ele, porque se en estivesse na delta você acha que iam me defender? [...] Depois que passei para alfa passei a ser mais respeitado até. Mais respeito. (Entrevistado 1)

(30) "Eu não tenho muito a reclamar não, eu aprendi muito com o pessoal aí, claro que desavença todo serviço tem, desavença, falta de comunicação tem, agora com relação a problema com funcionário seu tive acho que não levou a coisa séria, foi resolvida na mesma hora, então não tive problema. (Entrevistado 6)

No ambiente primarizado, os entrevistados se sentem mais protegidos e respeitados como profissionais, o que fica evidente pelo recurso do interdiscurso ("se eu estivesse na delta você acha que iam me defender?”). Todavia, não parece haver um sistema institucionalizado de regulação de conflitos na alfa, sendo eles resolvidos de maneira informal (texto 30). Os canais formalizados, via sindicato, por exemplo, ficam em segundo plano:

(31) O sindicato, o sindicado, eu não concordo muito com ele não. (Entrevistado 4)

(32) A gente tem um convênio odontológico, que a gente não tinha, a bolsa escolar, por enquanto minha filha está estudando ainda [...]. (Entrevistado 1)

Após a primarização, os entrevistados passaram a pertencer a outro sindicato, o mesmo dos demais trabalhadores da alfa. Os benefícios que os empregados passaram a desfrutar pela intervenção do sindicato - como o convênio odontológico e a bolsa escolar, explicitamente citados - distorcem o papel dessa organização, que passa a ser vista de forma esvaziada, apenas como intermediadora dos benefícios, o que confirma dados de pesquisas recentes, como a de Magalhães et al. (2011).

Os entrevistados criaram diversas expectativas a respeito de poder usufruir os mesmos benefícios a que os empregados da contratante tinham acesso na época em que eram terceirizados, o que constitui uma fonte potencial de conflitos.

(33) E eu tenho meus filhos e o futuro deles né... aqui na alfa tem com certeza para crescer né, há, oportunidade tem muitas, tem bolsa, que como funcionário eu também posso concorrer a isso, mas eu não tenho condições para mexer com isso, mas os meus filhos? Eles estão estudando, são inteligentes, com certeza, eu não vou fazer, mas eles vão. já penso em conseguir uma bolsa integral pra minha filha estudar. (Entrevistado 4)

Quando o empregado não espera usufruir o benefício, percebe a possibilidade de usufruto pelos seus filhos. Ter esse benefício significa poder proporcionar para os filhos algo que não teriam condições de fornecer, pois existe para eles a possibilidade de estudar e de serem bem sucedidos, o que não deixa de ser também uma forma de satisfazer o próprio desejo por meio dos filhos. Porém, as oportunidades esbarram no fator escolaridade. Como os trabalhadores primarizados possuem um grau de escolaridade baixo, suas possibilidades de ascensão hierárquica são limitadas, e isso é uma potencial fonte de conflitos.

\section{Considerações finais}

Neste trabalho, o objetivo foi identificar as representações sociais das relações de trabalho de empregados em um contexto pós-primarização. Parte-se de um cenário em que as organizações, após adotarem a terceirização para incrementar a competitividade, passaram a primarizar as atividades antes terceirizadas como meio de melhorar a qualidade e a confiabilidade. Todavia, trata-se de um movimento ainda pouco estudado, principalmente no que se refere aos aspectos não objetivos do fenômeno. Os 
resultados da pesquisa mostram como o processo de primarização influenciou nas representações sociais dos trabalhadores. Em linhas gerais, os empregados percebem o trabalho de forma diferente de quando eram terceirizados, já que, após a primarização, convivendo em um ambiente profissional em que são visíveis e reconhecidos os públicos externo e interno da empresa contratante. A representação toma nova forma, apresentando-se como resgate da autoestima, orgulho de fazer parte da empresa para a qual trabalham, segurança e, sobretudo, inclusão social.

Essa aproximação formal fez com que os primarizados desenvolvessem o sentimento de inclusão, devido ao fato de na terceirização o contato ter sido distante da empresa contratante. A estabilidade é um ponto relevante no contexto pós-primarização, uma vez que, enquanto terceiros, viviam um quadro de desconforto, medo, instabilidade, já que os contratos eram por tempo determinado. Com a primarização, a preocupação é minimizada, trazendo a tranqüilidade e conforto. É importante destacar que, conforme relatado nas entrevistas, percebe-se que se criou uma expectativa quanto o aumento do salário que, mesmo com um pequeno aumento, não se confirmou. Todavia, esses empregados percebem melhores condições de trabalho, o que em parte ocorre por conta da melhoria do relacionamento com a chefia, e em parte ao desempenho de tarefas determinadas, o que permite mais eficiência.

É importante aqui retomar que a construção das representações sociais se dá a partir da comunicação e interação das idéias de um grupo específico, que reflete a realidade, que nesse caso, se constitui em um contexto de pós-primarização. Porém, é comum que os gestores das organizações não considerem as representações sociais um equívoco, já que se constituem como mobilizadoras de ações e que podem, muitas vezes, ser fatores impeditivos dos objetivos estipulados. Nesse sentido, o que se observou nessa pesquisa é que, ao adotar uma técnica de gestão como a primarização, os gestores precisam considerar o surgimento de elementos que podem ocasionar representações negativas no processo. Ao reconhecerem as representações sociais produzidas e reproduzidas a partir do ambiente organizacional, as empresas podem planejar os processos de gestão no intuito de proporcionar benefícios tanto para os empregados, ao estimular os grupos de trabalho, como para a organização, que ganha com o comprometimento e a qualidade na realização das tarefas.
Quanto às implicações dessa pesquisa para os estudos em gestão de pessoas, primeiro é preciso considerar a escassez de estudos nessa linha. Esse trabalho contribui no sentido de fomentar pesquisas em outros contextos de primarização. Por se tratar de uma pesquisa inicial, não se ignora as limitações que ela apresenta, entre as quais a ausência de uma perspectiva mais crítica em torno das análises. Contudo, o intuito nesse momento era apenas o de trazer a tona alguns elementos mais evidentes entre os trabalhadores no contexto em questão. Compreende-se que as questões trabalhistas, bem como as relações de trabalho, são as mais significativas nesses casos e, por isso, iniciativa foi, em primeiro lugar, compreender uma pouco a percepção desses trabalhadores sobre a complexidade e dinamismo envolvendo o processo de primarização. Nesse sentido, sugere-se que mais pesquisas sejam realizadas, com focos mais abrangentes como por exemplo, buscar compreender as perdas e os ganhos, mensuráveis ou não, em torno dos processos de primarização, bem como as implicações trabalhistas e gerenciais destacadas nesse contexto.

\section{Referências}

ALBORNOZ, S. O que é trabalho. São Paulo, Brasiliense, 1986. 100 p.

ANTUNES, R. Os sentidos do trabalho. 6. ed. São Paulo: Boitempo, 2002. 258 p.

BICUDO, V. R. Terceirização na Petrobrás: implicações sociais, gerenciais e políticas. In: ENCONTRO ANUAL DA ASSOCIAÇÃO NACIONAL DE PÓS-GRADUAÇÃO E PESQUISA EM ADMINISTRAÇÃ̃ O, XXVII, Atibaia. Anais... Atibaia: ANPAD, 2003.

BRASIL. Ministério da Fazenda. Pesquisa de emprego e desemprego. Brasília: SEADE/ DIEESE, 2008.

CAMPOS, P. H. F.; ROUQUETTE, M. Abordagem estrutural e componente afetivo das representações sociais. Psicologia: Reflexão e Crítica, Porto Alegre, v. 16, n. 3, p. 435-445, 2003.

\section{CARVALHO NETO, A. M. Relações de trabalho e negociação coletiva na virada do milênio: estudo em quatro setores dinâmicos da economia. Petrópolis: Vozes, 2001. 304 p.}

CASTRO, A. S.; BIM, E. A. A viabilidade da “desterceirização" (outsourcing reverse): um 
estudo de caso sobre reciclagem de componentes poluentes (baterias automotivas). Associação Brasileira de Custos. Disponível em <http://www. abcustos.org.br>. Acesso em: 20 jun. 2008.

CAVEDON, N. R.; PIRES, R. M. "O pão nosso de cada dia": as representações sociais sobre a vida familiar e profissional dos trabalhadores na indústria da panificação. In: ENCONTRO DA ASSOCIAÇÃO NACIONAL DOS PROGRAMAS DE PÓS-GRADUAÇÃO EM ADMINISTRAÇÃO, XXVIII, 2004, Curitiba. Anais... Curitiba: ANPAD, 2004.

CAVEDON, N. R.; FERRAZ, D. L. S.

Representações sociais e estratégia em pequenos comércios. RAE-eletrônica, São Paulo, v. 4, n. 1, art. 14, jan. /jul. 2005.

COSTA, F. B. Homens invisíveis: relatos de uma humilhação social. São Paulo: Globo, 2004. 254 p.

DALFIOR, S. D. R. Novas relações de trabalho: efeitos da inserção de cooperativas de especialidade médica em um hospital público do Espírito Santo. 137 f. 2002. Dissertação (Mestrado em Administração) -Faculdade de Ciências Econômicas, Universidade federal de Minas Gerais, Belo Horizonte, 2002.

ESPÍNDULA, D. H. P. ; SANTOS, M. F. S.

Representações sobre a adolescência a partir da ótica dos educadores sociais de adolescentes em conflito com a lei. Psicologia em Estudo, Maringá, v. 9, n. 3, p. 357-367, set./dez. 2004.

FIORIN, J. L. Elementos de análise do discurso. 9. ed. São Paulo: Contexto, 2000. 93 p.

FISCHER, R. M. Pondo os pingos nos "is" sobre as relações do trabalho e políticas de administração de recursos humanos. In: FLEURY, M. T. L.; FISCHER, R. M. (Org.). Processo e relações do trabalho no Brasil: movimento sindical, gestão e participação. 2. ed. São Paulo: Atlas, 1987. p. 19-50.

FLEURY, A. C. C. Organização do trabalho na indústria: recolocando a questão nos anos 80 . In: FLEURY, M. T. L.; FISCHER, R. M. (Org.). Processo e relações do trabalho no Brasil: movimento sindical, gestão e participação. 2. ed. São Paulo: Atlas, 1987. p. 51-66.

GALVÃO, A.; TRINDADE, E. A. Sistemas de relações de trabalho nos países avançados: principais características e mudanças recentes. In: DIEESE (Org.). Emprego e desenvolvimento tecnológico. Campinas: DIEESE/CESIT, 1999. p. 225-253.
GOMES, R.; MENDONÇA, E. A.; PONTES, M. L. As representações sociais e a experiência da doença. Cadernos de Saúde Pública, Rio de Janeiro, v. 18, n. 5, p. 1207-1214, set./out. 2002.

MAGALHÃES, Y. T.; SANTOS, A. R. G.; SALES, V. F. D.; SARAIVA, L. A. S. Primarização e relações de trabalho em uma empresa mineradora de Minas Gerais. Sociedade, Contabilidade e Gestão, Rio de Janeiro, v. 6, n. 1, p. 104-119, 2011.

MELO, M. C. O. L. Estratégias do trabalhador informático nas relações de trabalho. 1991. 411 f. 1991. (Tese, Professor Titular) - Faculdade de Ciências Econômicas, Universidade Federal de Minas Gerais, Belo Horizonte, 1991.

MELO, M. C. O. L. Estratégias do (s) empregado (s) no cotidiano das relações de trabalho: a construção de processos de auto-regulação. In: DAVEL, E.; VASCONCELOS, J. G. M. (Org.). "Recursos humanos" e subjetividade. 4. ed. Petrópolis: Vozes, 2002. 260 p.

MELO, M. C. O. L.; CARVALHO NETO, A. M. Negociação coletiva e relações de trabalho: $\mathrm{O}$ debate atual. São Paulo: ABET, 1998. 112 p.

MINAYO, M. C. S. O desafio do conhecimento: pesquisa qualitativa em saúde. 9. ed. São Paulo: Hucitec, 2006. 406 p.

MINAYO, M. C. S. (Org.). Pesquisa social: teoria, método e criatividade. 22. ed. Petrópolis: Vozes, 2007.80 p.

MOSCOVICI, S. Representações sociais: investigações em psicologia social. 5. ed. Petrópolis: Vozes, 2007. 404 p.

OLIVEIRA, F. O.; WERBA, G. C. Representações sociais. In: JACQUES, M. G. C.; STREY, M. N. ; BERNARDES, M. G.; GUARESCHI, P. A.; CARLOS, S. A.; FONSECA, T. M. G. (Org.).

Psicologia social contemporânea. 4. ed. Petrópolis: Vozes, 2000. p. 104-117.

PÊCHEUX, M. Semântica e discurso. 5. ed. Campinas: UNICAMP 2014. 288 p.

SÁ, C. P. Representações sociais: o conceito e o estado atual da teoria. In: SPINK, M. J. (Org.). O conhecimento no cotidiano: as representações sociais na perspectiva da psicologia social. São Paulo: Brasiliense, 1993. p. 19-45.

SARAIVA, L. A. S.; MERCÊS, R. E. Terceirização na gestão da manutenção: estudo de caso de uma mineradora. Revista de Administração da 
UNIMEP, Piracicaba, v. 11, n. 1, p. 1-24, jan. /abr. 2013.

SPINK, M. J. O conceito de representação social na abordagem psicossocial. Cadernos de Saúde Pública, Rio de Janeiro, v. 9, n. 3, p. 300-308, jul./ set. 1993.

TEIXEIRA, M. C. T. V.; SCHULZE, C. M. N.; CAMARGO, B. V. Representações sociais sobre a saúde na velhice: um diagnóstico psicossocial na rede básica de saúde. Estudos de Psicologia, Natal, v. 7, n. 2, p. 351-359, 2002.

XAVIER, R. Representação social e ideologia: conceitos intercambiáveis? Psicologia \& Sociedade, Porto Alegre, v. 14, n. 2, p. 18-47, jul./dez. 2002. 